\title{
DETERMINAÇÃO DA ÉPOCA DA DESOVA E MATURAC̣ĀO DO JUNDIÁ, Rhamdia sapo, BASEADO NO IGS E EM ESTUDO MORFOCITOLOGICO DAS GONODAS
}

Ilca Marion Knewitz Bossemeyer

Departamento de Biologia. Centro de Ciencias Naturais e Exatas.UFSM. Santa Maria, RS.

George A. Barton Hall

Departamento de Zootecnia. Centro de Ciências Rurais. UFSM. Santa Ma ria, RS.

RESUMO

Mudanças estacionais do ovócito e determinação da época de desova do jundiá (Rhamdia sapo) foram estudadas neste trabalho,empre gando-se os parāmetros IGS (ïndice gōnado-somätico), CPN (coeficien te ponderal mensal da proporção de ovōcitos) e CPT (ārea ocupada pe los ovōcitos em cada estādio).

Conclui-se que as fémeas de Rhamdia sapo apresentam longo periodo reprodutivo (agosto a fevereiro) com duas fases de acentua da atividade reprodutiva (agosto-setembro e janeiro-fevereiro).

SUMMARY

BOSSEMEYER, I.M.K. and HALL,G.A.B., 1980. Determination of the time of spawning and maturation of the jundiā, Rhamdia sapo, based on the Gonado-Somatic index (GSI) and the morphocy tologic study of the gonads. Ciência e Natura (2):133-151.

Seasonal changes of the oocyte and the determination of the time of spawning of Rhamdia sapo are studied in this paper by the use of the Gonado-somatic Index (IGS), the monthly weight proportion of oocytes coeficient (CPN) and the oocyte area in each of its stages of development (CPT) as parameters.

The conclusion drawn was that Rhamdia sapo females have a long reproductive period (august to february), in which two phases of enhanced reproductive activity were detected (august-september and january-february).

INTRODUÇAO

Basicamente, em Piscicultura, os problemas giram em torno da reprodução, do controle das doenças e da nutrição.

A maturidade sexual de alguns peixes é atingida precocemen te, enquanto que a de outros dá-se quase ao final de sua vida. A na tureza cīclica da atividade reprodutiva ē mais evidente nas fémeas do que nos machos, havendo, nuns e noutros, grande variação, no que tan ge à freqüéncia do ciclo reprodutivo, número das desovas e época do 
ano em que estas ocorrem.

A influência do fotoperiodo, da temperatura e da precipi tação pluviométrica, sobre o ciclo reprodutivo dos peixes, tem sido avaliada em numerosos trabalhos que se assentam, entretanto, no pré vio conhecimento da fisiologia reprodutiva, através do estudo das características morfológicas das gônodas.

Habitualmente, o estudo do comportamento reprodutivo dos animais faz-se em seu habitat. O habitat aquático, entretanto, impõe inümeros óbices para o investigador afeito a averiguar a desova.Por isso, maturação e desova minuciam-se, o mais das vezes, pelo estudo anatômico e morfocitológico das gōnadas dos peixes.

No presente trabalho, utilizou-se o Jundiá (Rhamdia sapo), peixe nativo e dos mais comuns no Rio Grande do Sul. Por sua aceita ção no mercado consumidor, graçás à qualidade de sua carne,e também pelo decréscimo de nummero que ele tem sofrido em suas reservas natu rais, fomos levados a investigar seu padrão reprodutivo, com base no estudo morfocitológico de suas gônadas.

As bases do desenvolvimento com a reprodução dos peixes têm sido enfocado por diversos autores (HOAR, 11; JAMES, 12;PIGNALBERI, 18; SILVA, 22).

FRANCHI (5), descrevendo a morfologia e a histologia dos ovārios de diversos grupos de peixes, observou que ovogēnese mantēm - se durante a vida adulta, apenas em algumas espécies. Na maioria dos teleósteos, a ovogénese parece ocorrer ciclicamente e apresentar um pico breve após a desova.

MEYER et alii (17) constataram que a época e a duração da estação de desova do channel catfish (Ictalurus punctatus) varia de ano para ano e entre localidades. Referiram-se, também, ao reconhe cimento dos sexos, o qual se deve basear na observação da região ge nital, jā que a fémea apresenta genitais arredondados e o macho uma papila carnosa.

SAKSENA \& BHARGAVA (i9), com o estudo quantitativo de cor pos atrésicos e folículos pós-ovulatōrios, precisaram a periodicida de do Glossogobius giuris.

BARA (1), em meticuloso estudo sobre mudanças histológicas e citolögicas, no ovārio do Scomber scomber, estabeleceu onze está dios no desenvolvimento do ovócito, destacando as modificações do nū cleo e do citoplasma.

GANDOLFI \& ORSINI (7) mostraram, em seu trabalho com Mugit saliens, que peixes capturados no outono, inverno e inicio da prima vera tinham um indice gônado-somātico (IGS) muito baixo, com varia bilidade minima na população, sendo que a fêmea, no verão, apresenta 
va o valor máximo do IGS, da ordem de $19,54 \%$.

0 linguado (Pleuronectes platessa) foi estudado por BARR (2), em Millport, Escōcia, onde as temperaturas mēdias de inverno e verão são, respectivamente, $3,3^{\circ}$ e $17,8^{\circ} \mathrm{C}$. 0 autor verificou que 0 IGS maior, ocorrido de fevereiro a março, foi de, aproximadamente, $18 \%$ e que, durante o desenvolvimento, o ovócito passava por seis diferen tes estádios, sendo o diāmetro māximo alcançado no último estādio, correspondente ao ovārio maduro, foi de 1.400 micrōmetros.

Segundo MACKAY (1), o gobião (Hypseleotris galii) tem, co mo a maioria dos peixes teleósteos de àgua doce temperada, um ciclo reprodutivo anual, no qual a reprodução se dā, de novembro a janei ro. Baseou o autor suas conclusões nos valores do IGS (cujo valor má ximo foi de $12 \%$ ) e nas mudanças de diāmetro do ovōcito.

SILVA (22), estudando os aspectos da biologiade um tipo de arenque (Sprattus sprattus), determinou o tempo e a duração da época da desova, baseando-se no IGS (de aproximadamente 10\%) e no aspecto macroscópico das gônadas. Verificou, também que o indice de matura ção tem lugar a baixas temperaturas.

JAMES (12), ao estudar as mudanças estacionais das gônadas de duas espécies de peixes (Lepomis macrochirus e Huro salmoides), baseando-se em estudos histológicos e no IGS, constatou um aumento no tamanho das gônadas, relacionado com a elevação da temperatura da àgua na primavera; observou, outrossim, que a estrutura anatómica e histolōgica do ovārio refletia mudanças nutricionais e de idade. 0 maior IGS registrado para a Lepomis macrochirus (prōximo a 10\%)coin cidiu com temperatura de maior elevação na primavera.

GODINHO et alii (8), usando como parāmetro o IGS, determi naram a curva de maturação do mandi, registrnado um valor mäximo de $8,63 \%$.

O curimbatá (Prochilodus scrofa) e o sābalo (Prochilodus platensis) foram estudados, quanto ao seu tipo reprodutivo, respec tivamente, por SCHUBART (20) e PIGNALBERI (18) que determinaram os seus estados sexuais e os incluirram em etapas de 0 (zero) a $X(d e z)$. 0 aspecto da gōnada, em cada etapa, foi descrito, e o valor do IGS determinado. 0 valor māximo desse indice, para o curimbatá, foi de $20 \%$ e, para o sábalo, de $25 \%$. A desova do primeiro ocorreu nos meses de novembro a fevereiro, enquanto que o segundo apresentou dois pe ríodos distintos de atividade sexual: um, na primavera e outro, no fim do verão.

GODINHO et alii (9), ao estudarem o mandi, determinaram quatro estádios de diferenciação do ovōcito e sugeriram cinco está dios, baseando-se em características anatōmicas e fisiológicas. 
As mudanças ocorridas no ovārio do Paracentropristes cabri Zza, ao longo dos processos de previtelogénese e vitelogénese, foram incluīidas em sete estādios, por ZANUY \& CARRILLO (24).

BASILE-MARTINS et alii (3) correlacionaram fatores abiōti cos e maturação dos ovārios, esta expressa por valores médios do IGS, mostrando a existēncia de correlação positiva entre esse indice e precipitações pluviométricas, o mesmo acontecendo com a temperatura da àgua e o nível do rio.

MATSUSHIMA \& FELIX (16) submeteram o Carassius carassius à chuva artificial e à àgua com temperaturas elevadas reguladas, ob tendo com isso um aumento na atividade reprodutora.

Exemplos de funções que são induzidas por um longo fotope ríodo incluem eventos complexos reprodutivos e migratörios em muitas espēcies de aves, assim como estro, na doninha, e conclusão da game togênese e comportamento reprodutivo, em alguns peixes (FARNER, 4 ).

Em exaustiva revisão, HOAR (11) demonstrou serem fotoperío do e temperatura os reguladores ambientais para os peixes de àguas temperadas e frias. Acentuou, porém, que a importância relativa des ses fatores varia marcadamente nas diferentes espécies. 0 efeito re gulador ambiental varia segundo o estádio de maturação gonadal,poden do ser menos ou mais acentuado, de acordo com o período em que se en contra o animal. Considere-se, ainda, que as respostas ao fator am biental podem ser dadas de forma diferente pelos machos e pelas fó meas de uma mesma espēcie. Ocasionalmente, o processo gametogenéti co, em determinados estádios da maturação gonadal, pode independer dos fatores ambientais.

HAYDOCK (10) notou que, na Bairdiezza icistia, com fotope rỉodo e temperatura controlados, em combinaçoes com alimento abundan te, havia antecipação da maturação da gônada. Longos fotoperỉodos(16 a $24 \mathrm{~h}$ ) e água com temperatura de $22^{\circ} \mathrm{C}$ aceleravam a maturaçãogonadal. Segundo entende esse autor, IGS é medida que indica acuradamente a aptidão reprodutiva do peixe.

FRAPS (6) divide as mudanças ovarianas anuais, que culmi nam com a estação reprodutiva, em duas fases: folicular ou prē-ovu latōria e ovulatōria; afirma, também, que, na grande maioria das es pécies animais, o fator externo decisivo, no desenvolvimento das gô nadas, parece ser a duração do fotoperíodo.

Autores como KAYA \& HASLER (13) reconhecem uma correlação, em latitudes temperadas, entre os períodos reprodutivos da primave ra e do verão em muitas espécies de peixes, com os dias mais quentes e mais longos destas estações.

SHIRAISHI \& FUKUDA (21), em sua monografia, compararamama 
turidade de salmonideos em fotoperíodos de duração diversa.

os efeitos de vārias combinações de fotoperīodo e tempera tura, no desenvolvimento gonadal, têm sido examinados em vărias es pécies de teleósteos. Em alguns peixes, värios autores mostraramo fator dominante na regulação da reprodução, enquanto que, em outros, o fotoperiodo é que se mostrou mais importante (MACKAY, 15). Em seu experimento com Hypseleotris galii, o mesmo autor obteve resultados que demonstraram ser a temperatura de importāncia primária para a ma nutenção da vitelogēnese. SUNDARARAJ \& SEHGAL (23), de outra parte, mostraram que o ovārio do peixe-gato (Heteropneustes fossizio) apre sentou recrudescéncia, quando o animal foi submetido a um longo fo toperiodo ou a um fotoperíodo gradualmente crescente, evidenciando que a temperatura, nessa resposta fotossexual tem papel meramente fa cilitatōrio.

MATERIAL E METODO

Foram estudados exemplares de Jundiā provenientes de rios e de açudes próximos da cidade de Santa Maria, no Rio Grande do Sul, coletados no período de maio de 1975 a abril de 1976, em ārea deli mitada pelo triāngulo cujos coordenadas são: Lat. $29^{\circ} 27^{\prime} \mathrm{S}$-Long. $53^{\circ} 46^{\prime}$ W; Lat. $30^{\circ} 00^{\prime} \mathrm{S}$-Long. $53^{\circ} 47^{\prime} \mathrm{W}$ e Lat. $29^{\circ} 55^{\prime} \mathrm{S}-$ Long. $53^{\circ} 34^{\prime} \mathrm{W}$.

Mensalmente foram coletadas, em média, 10 fémeas, comope so mînimo de $180 \mathrm{~g}$, perfazendo 114 animais de experimentação. Condu zidas com vida ao laboratōrio, eram lá sacrificadas, apōs o quê, ano tava-se seu comprimento total em centímetros, com a aproximaçăo de milímetros, e seu peso em gramas. A seguir, procedia-se à ovarietec tomia e eram as gōnadas pesadas, com a aproximação de decigramas.

0 îndice gônado-somático (IGS) calculado por (peso da gô nada/peso do peixe) X 100 foi determinado para cada fêmea, a fim de averiguar o indice de condição gonadal. O efeito do mês, sobre as me didas do desenvolvimento ponderal e condição gonadal, estudou-se pe la anālise de variāncia.

Frações de ovārios foram fixadas no lïquido TELLYENSNIESKY durante 24 horas, lavadas em āgua corrente por igual tempo, submeti das à sērie de àlcoois para desidratação, impregnadas em parafina e xilol, cortadas em secções entre 8 e 10 micrômetros de espessura e coradas pelo método da hematoxilina-eosina.

Foram selecionadas 10 lâminas de cada animal e, após o mi nucioso estudo destes, possivel foi considerar-se a existéncia de 5 estágios no desenvolvimento dos ovōcitos, a saber:

Estädio I

Compreende oogōnias e ovōcitos, nos quais o citoplasma é 
visível e basōfilo, com tamanho máximo de 53 micrōmetros e núcleore lativamente grande.

Estádio II

Compreende ovōcitos com tamanho igual ou superior a $54 \mathrm{mi}$ crōmetros, citoplasma mais volumoso, ainda basōfilo e com revestimen to folicular formado pela granulosa e teca, constituídas por células planas.

Estádio III

Neste estādio o citoplasma torna-se acidófilo; a camada celular folicular interna, correspondente à granulosa, torna-se al ta; a zona pelúcida esboça-se, e, sucessivamente, ao final do está dio, dá-se o aparecimento de pequenas vesiculas vitelinas que se 10 calizam na periferia do citoplasma do ovócito, imediatamente subja centes à zona pelúcida.

Estädio IV

Registra o início da vitelogênese, com a deposição de grâa nulos de vitelo, a partir da periferia do citoplasma.

Estádio V

Mostra ovōcitos em vitelogênse avançada, a seqüência dopro cesso até o final amadurecimento dessas células, a julgar pelo total preenchimento do seu citoplasma por grânulos de vitelo.

As figuras $1,2,3$ e 4 mostram detalhes de células em vā rios dos estādios descritos.

0 estudo do tamanho dos ovócitos, nos diferentes estádios considerados, fez-se pela medida dos diâmetros de 100 ovócitos de ca da estādio escolhidos ao acaso e provenientes de diversas fêmeas, com o auxîlio da ocular micrométrica, com a magnificação de $125 \mathrm{X}$. Com estes dados foi feito o cālculo do tamanho médio, mỉnimo e máxi mo dos ovócitos, seu desvio padrão e o coeficiente de variação por estādio.

A contagem dos ovócitos, nos diferentes estádios, fez-se, em cada peixe, em 5 campos microscópicos com a magnificação de $125 \mathrm{X}$ e delimitados pelo retĩculo da ocular micrométrica. Essa contagem por campo foi expressa pela percentagem dos mesmos por estādio (PN). Uti lizando-se o tamanho médio de cada estādio, calculou-se o percentual de cada campo ocupado por ovōcitos de cada estādio (PA).

Foram estimados coeficientes ponderais da proporção de ovō citos de cada estādio (CPN) e da ārea proporcional ocupada pelos ovō citos de cada estádio (CPA), multiplicando-se os valores PN e PA, res pectivamente, pelo número do estádio representado. Os valores CPN e CPA serviram, apōs a aplicação das anālises estatīsticas (especifí cadas a seguir), para avaliar a efetividade das características cito 
lögicas, utilizadas para prever diferenças seqüenciais no desenvol vimento dos ovōcitos.

Foram calculadas as correlações simples entre peso da gô nada e IGS com os parāmetros CPN e CPA.

Para transformar os valores percentuais numa distribuição normal, fez-se a correção preconizada:

Valor corrigido $=\operatorname{arc}$ sen $\sqrt{\text { valor em } \%}$

Efetuaram-se anālises estatĩsticas, atravēs da anālise de variância, para determinar o efeito de mês sobre peso e comprimento do peixe, peso da gônada e IGS. Os valores de PN e PA foram submeti dos ao teste do $\chi^{2}$ para averiguar se havia efeito do mês sobre estes parâmetros. Os valores corrigidos de CPN e CPA sofreram anālise de variância para averiguar o efeito do mês. Quando se registraram dife renças significativas $(P<0,05)$ pelas anālises de variância, o tés te de DUNCAN foi aplicado para parcelar estas diferenças.

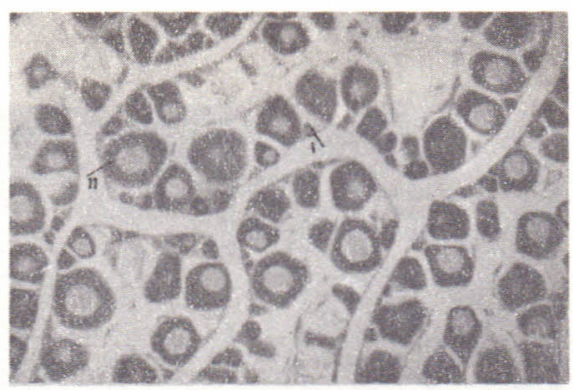

Figura 1. Corte de ovário mostrando aspectos da distri buição de ovócitos nos estádios I e II nas ị melas ovígeras. Aumento de, aproximadamente, $125 \times$.

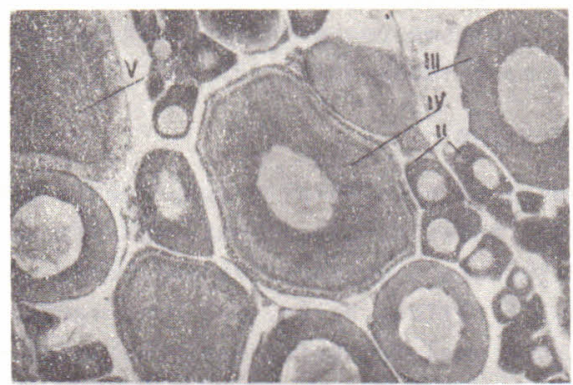

Figura 2. Corte de ovārio onde se observam ovōcitos nos estādios II, III, IV e V. Aumento de, aproxima. damente, $125 \mathrm{X}$. 


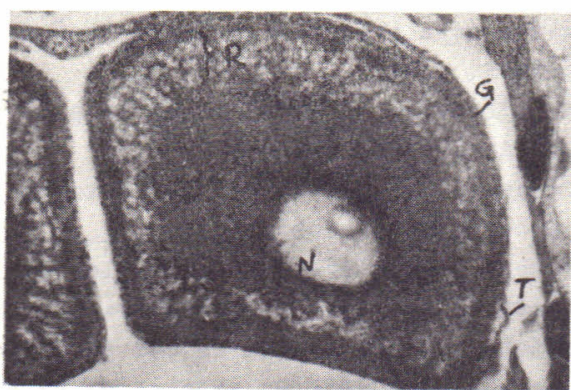

Figura 3. Corte de ovārio mostrando ovōcito de estádio IV, vendo-se a camada granulosa. (G), a teca (T), região do citoplasma periférico onde se encontram as vesículas vitelina e grânulos de vitelo (R) e núcleo (N). Aumento de aproxima damente, $312 \mathrm{X}$.

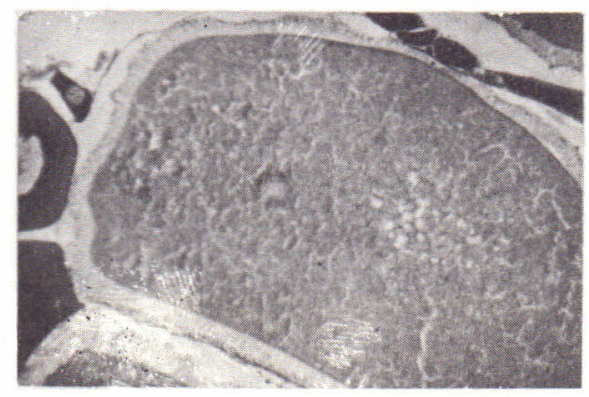

Figura 4. Corte de ovārio mostrando ovócițo do estádio $\checkmark$ no qual nota-se o preenchimento total do ci toplasma por grânulos de vitelo. Aumento de, aproximadamente, $125 \mathrm{X}$.

RESULTADOS E DISCUSSAOO

As médias de peso total e comprimento dos exemplares cole tados nos diversos meses do experimento constam na Tabela I. Nota-se que não houve diferença significativa nas médias do peso e do compri mento $(P>0,05)$. E nítido, porém, que este variou menos do que 0 peso total, sobre o qual têm maior repercussão as variações da ali mentação.

As médias mensais do peso do ovārio e do IGS são apresen tadas na Tabela II. 
TABELA I

Número capturado, com valores médios mensais e respecti vos desvios padrões (DP) do peso total (g) e comprimento (cm) das fé meas de $R$. sapo coletadas na região de Santa Maria, RS (maio de 1975abril 1976).

\begin{tabular}{|c|c|c|c|c|c|}
\hline \multirow[b]{2}{*}{ MES } & \multirow{2}{*}{$\begin{array}{c}\text { NOMERO } \\
\text { de } \\
\text { EXEMPLARES }\end{array}$} & \multicolumn{2}{|c|}{ PESO TOTAL } & \multicolumn{2}{|c|}{ COMPR IMENTO } \\
\hline & & MEDIA (g) & DP & $\operatorname{MEDIA}(\mathrm{cm})$ & $D P$ \\
\hline Maio- 75 & 17 & 451,77 & 71,80 & 34,07 & 1,20 \\
\hline Junho & 6 & 735,83 & 120,85 & 38,75 & 2,02 \\
\hline Julho & 11 & 629,09 & 89,25 & 37,06 & 1,49 \\
\hline Agos to & 8 & 485,00 & 104,66 & 37,27 & 1,75 \\
\hline Setembro & 10 & 746,70 & 93,61 & 39,25 & 1,57 \\
\hline Outubro & 8 & 557,00 & 104,66 & 35,68 & 1,75 \\
\hline Novembro & 10 & 673,10 & 93,61 & $\cdot 38,90$ & 1,57 \\
\hline Dezembro & 8 & 537,25 & 104,66 & 36,56 & 1,75 \\
\hline Janeiro -76 & 6 & 603,33 & 120,85 & 38,51 & 2,02 \\
\hline Fevereiro & 9 & 649,11 & 98,67 & 38,37 & 1,65 \\
\hline Março & 11 & 621,63 & 89,25 & 38,43 & 1,49 \\
\hline Abril & 10 & 389,10 & 93,61 & 34,54 & 1,57 \\
\hline
\end{tabular}

TABELA II

Valores médios mensais do peso das gônadas (g) e do IGS (\%) das fêmeas de $R$. sapo coletadas na região de Santa Maria, RS (maio 1975 - abril 1976).

\begin{tabular}{|c|c|c|c|c|}
\hline \multirow[b]{2}{*}{ MES } & \multicolumn{2}{|c|}{ PESO DA GŌNADA } & \multicolumn{2}{|c|}{ I G S } \\
\hline & MEDIA (g) & DP & MEDIA (\%) & $\mathrm{DP}$ \\
\hline Maio- 75 & $4,57^{C}$ * & 3,30 & $0,991^{a}$ & 0,54 \\
\hline Junho & $17,06^{\mathrm{bc}}$ & 5,50 & $1,871^{a b}$ & 0,37 \\
\hline Jutho & $10,64^{b c}$ & 4,10 & $1,607^{a b}$ & 0,67 \\
\hline Agosto & $40,35^{a}$ & 2,83 & $7,206^{d}$ & 0,79 \\
\hline Setembro & $43,85^{a}$ & 4,30 & $5,504^{c d}$ & 0,71 \\
\hline outubro & $16,07^{\mathrm{bc}}$ & 2,83 & $2,811^{a b}$ & 0,79 \\
\hline Novembro & $20,12^{b}$ & 4,30 & $2,27^{a b}$ & 0,71 \\
\hline Dezembro & $23,25^{b}$ & 2,83 & $3,550^{b c}$ & 0,79 \\
\hline Janeiro -76 & $46,43^{a}$ & 5,50 & $7,752^{d}$ & 0,37 \\
\hline Fevereiro & $37,78^{a}$ & 4,53 & $5,490^{c d}$ & 0,75 \\
\hline Março & $14,85^{b c}$ & 4,10 & $2,375^{a b}$ & 0,67 \\
\hline Abril & $4,83^{C}$ & 4,30 & $1,166^{a}$ & 0,71 \\
\hline
\end{tabular}

* Valores na mesma coluna, seguidos pela mesma letra, não diferem significativa mente $(P>0,05)$ 
A Tabela III mostra os quadrados médios dos parāmetros que constam nas duas tabelas anteriores.

\section{TABELA III}

Quadrados médios da añ̄lise de variāncia de mês para peso total, comprimento, peso das gōnadas e IGS das fēmeas de $R$. sapo co letadas na região de Santa Maria, RS (maio 1975 - abril 1976).

\begin{tabular}{lrrrrrr}
\hline \hline \multirow{2}{*}{ FONTE DE } & GL & $\begin{array}{c}\text { PESO TOTAL } \\
\text { DO }\end{array}$ & PEIXE & COMPR. DO & PESO DA & PEIXE \\
\hline Tratamento & 11 & 111390 & 34,4771 & $3877,36 *$ & $48,5390 *$ \\
Erro & 102 & 87629 & 24,5550 & 184,77 & 5,0064 \\
\hline
\end{tabular}

* $(P<0,01)$

As mudanças no peso médio das gônadas mostraram a existēn cia de dois períodos com valores significativamente maiores $(P<0,05)$ : agosto-setembro e janeiro-fevereiro. Valores minimos para o peso më dio foram registrados em abril e maio, que diferiram significativa mente $(P<0,05)$ dos demais meses.

O IGS, em geral, mostrou as mesmas tendencias que o peso da gônada, uma vez que este indice é calculado a partir do peso dos ovārios. Os maiores valores de IGS $(P<0,05)$ foram registrados nos meses de agosto, setembro, janeiro e fevereiro; o mês de dezembro, apesar de registrar IGS mais baixo, não diferiu significativamente $(P>0,05)$ dos meses de fevereiro ou setembro, conforme mostra tes te de DUNCAN.

Pela anälise dos valores do IGS, obtidos durante o experi mento, o ciclo de desenvolvimento gonadal apresentou as seguintes fa ses:

a) Quiescência gonadal em abril, maio, junho, e juiho, com IGS mëdio inferior a $25 \%$.

b) Rápido aumento no desenvolvimento gonadal nos meses de agosto e setembro, com IGS mëdio de 7,21 e $5,50 \%$, res pectivamente.

c) Diminuição no desenvolvimento gonadal nos meses seguin tes (outubro, novenbro e dezembro), registrada por va lares de IGS que oscilaram entre 2,27 e $3,55 \%$.

d) Um segundo período de desenvolvimento gonadal, com novo aumento do IGS, que atingiu $7,25 \%$, em janeiro, e $5,49 \%$, em fevereiro.

e) Nova diminuição no desenvolvimento gonadal a partir de março. 
Os valores de IGS mostraram suas maiores variações nos exem plares coletados entre os meses de setembro e janeiro. Durante a quies cência gonadal (março, abril, maio, junho e julho), os valores de IGS foram uniformemente baixos. Aconteceu o inverso nos meses de agos to/setembro e janeiro/fevereiro, onde os valores de IGS foram unifor memente altos.

Autores como GANDOLFI \& ORSINI (7), encontraram os valores altos de IGS para Mugiz saliens somente durante o verão.

vārios autores $(8,12,14 \mathrm{e}, 22)$ obtiveram, em fêmeas madu ras, durante as fases de maior desenvolvimento gonadal, valores de IGS próximos aos obtidos para o jundiá, no presente trabalho. BARR (2), com Pteuronectes platessa e SCHUBART (20), com Prochizodus scrofa, referem, em seus trabalhos, valores de IGS muito superiores aos obtidos neste experimento.

A Tabela IV mostra os diāmetros mēdios dos ovōcitos nos cinco estādios aqui considerados.

TABELA IV

Diâmetro médio dos ovócitos ( $\mu \mathrm{m})$ nos cinco estádios do seu desenvolvimento, com desvio padrão (DP) e coeficiente de variação(\%) nas fêmeas de $R$. sapo coletadas na região de Santa Maria, RS (maio 1975 - abri1 1976).

\begin{tabular}{cccc}
\hline ESTADIOS & $\begin{array}{c}\text { TAMANHO MEDIO } \\
(\mu \mathrm{m})\end{array}$ & DP & $\begin{array}{c}\text { COEF.DE VARIAÇAO } \\
(\%)\end{array}$ \\
\hline I & 35,45 & 10,58 & 29,85 \\
II & 145,86 & 61,57 & 41,92 \\
I I I & 250,26 & 35,50 & 14,18 \\
IV & 343,05 & 55,97 & 16,31 \\
V & 803,04 & 102,86 & 12,80 \\
\hline
\end{tabular}

Com a anālise dos valores obtidos para cada estädio,obser va-se que houve um período, que vai do estädio I ao IV, em que o au mento foi gradual, correspondendo a um crescimento relativamente len to, seguido de outro de crescimento rāpido, correspondente ao final da vitelogênese, quando se dá o preenchimento do ovōcito pelo vite 10 .

KAYA \& HASLER (13) e SUNDARARAJ \& SEHGAL (23), que calcu laram o diàmetro dos ovócitos do Lepomis cyanellus e Heteropneustes fossilis, respectivamente, obtiveram, para os estādios de maturação correspondentes ao estādio $V$ deste trabalho, valores prōximos ( 800 a $1000 \mu \mathrm{m}$ para o L. cyanelzus e $600 \mu \mathrm{m}$ para o H. fossizis) àqueles aqui relatados para o jundiā. SHIRAISHI \& FUKUDA (21), por sua vez, 
estudando ovōcitos de Salmo gairdnerii, Oncorhynchus nerka e Salve linus fontinalis, assinalaram diāmetros muito superiores, da ordem de cerca de $3 \mathrm{~mm}$.

Constam na Tabela $V$ as percentagens mensais dos ovōcitos em cada estádio. A anālise, do qui-quadrado $\left(x^{2}\right)$ revelou diferenças significativas dentro de todos os estádios, indicando que o fator mês afetou a proporção dos ovōcitos nestes estádios. O maior grau de significância ocorreu nos estádios II, III e V.

TABELA $V$

Percentagem média mensal dos ovōcitos com teste $x^{2}$, em ca da estādio, nas fêmeas de $R$. sapo coletadas na região de Santa Ma ria, RS (maio 1975 - abril 1976).

\begin{tabular}{lrrrrr}
\hline \multirow{2}{*}{ MES } & \multicolumn{5}{c}{ ESTADI0 } \\
\cline { 2 - 6 } & \multicolumn{1}{c}{ I } & II & II I & \multicolumn{1}{c}{ IV } & \multicolumn{1}{c}{ I } \\
\hline Maio- 75 & 23,65 & 67,28 & 3,97 & 0,13 & 4,96 \\
Junho & 20,24 & 59,88 & 5,44 & 0,00 & 14,47 \\
Julho & 20,41 & 55,91 & 16,27 & 2,37 & 5,05 \\
Agosto & 15,74 & 47,36 & 4,02 & 3,64 & 29,22 \\
Setembro & 11,30 & 32,06 & 2,73 & 5,53 & 48,29 \\
Outubro & 19,41 & 53,87 & 5,95 & 3,54 & 16,14 \\
Novembro & 14,50 & 65,17 & 2,20 & 1,11 & 16,97 \\
Dezembro & 12,90 & 63,72 & 2,55 & 1,68 & 19,13 \\
Janeiro & 5,94 & 31,80 & 1,03 & 1,61 & 60,28 \\
Fevereiro & 5,97 & 41,99 & 1,04 & 0,44 & 50,37 \\
Março & 9,95 & 64,35 & 2,41 & 6,45 & 16,67 \\
Abril & 16,47 & 76,16 & 0,19 & 0,00 & 7,04 \\
\hline Mëdia & 14,70 & 54,97 & 4,07 & 2,21 & 24,05 \\
$\chi^{2}$ & 24,49 & 29,95 & 49,84 & 23,49 & 162,85 \\
\hline
\end{tabular}

A análise dos resultados apontou maiores proporções de ovó citos nos estádios I e II, durante a quiescência gonadal, como era de se esperar. Corrobora este fato a assertiva de FRANCHI (5) de que, em muitos teleósteos, hā alta freqüência de divisões mitóticas após a desova, para a formação de novos ovócitos.

0 encontro de pequeno número de ovōcitos nos estádios III e IV parece sugerir que a transformação dos ovōcitos nos estādios ini ciais em estádio $V$ ocorre rapidamente. Esta constatação foi também observada por BARR (2) e JAMES (12).

Os meses de agosto e setembro mostraram grande proporção de ovócitos maduros (29 a 48\%, respectivamente). Esta proporção caiu 
para menos de $20 \%$ nos meses subseqüentes, voltando a aumentar em ja neiro e fevereiro (quando alcançou valores de 60 e $50 \%$ respectiva mente). As maiores percentagens de ovócitos, no estádio V, coincidi ram com os meses em que se registraram as menores percentagens de ovōcitos nos estādios I e II, em razão da acelerada transformação dos ovōcitos destes estādios iniciais em ovócitos maduros.

A Tabela VI mostra percentagem mensal da ārea da gonada ocu pada pelos ovōcitos nos respectivos estádios. Os valores desta tabe la ratificam os resultados da anterior, apontando maiores àreas ocu padas por ovócitos no estādio $V$, nos meses de agosto e setembro e, novembro, em janeiro e fevereiro. Foram significativas as variações mensais dentro dos estādios II e V, como pode ser verificado pelos resultados do teste $x^{2}$.

TABELA VI

Percentagem mensal da àrea ocupada pelos ovōcitos, com tes te $x^{2}$ de cada estādio, nas fêmeas de $R$. sapo coletadas na região de Santa Maria, RS (maio 19?5 - abril 1976).

\begin{tabular}{|c|c|c|c|c|c|}
\hline \multirow[b]{2}{*}{ MEES } & \multicolumn{4}{|c|}{ ESTADIO } & \multirow[b]{2}{*}{ V } \\
\hline & I & I I & I I I & IV & \\
\hline Maio -75 & 5,40 & 62,91 & 6,34 & 0,30 & 25,41 \\
\hline Junho & 3,20 & 38,44 & 6,07 & 0,00 & 51,80 \\
\hline Julho & 4,06 & 45,77 & 22,85 & 4,56 & 22,76 \\
\hline Agos to & 1,68 & 22,82 & 3,03 & 3,76 & 70,71 \\
\hline Setembro & 0,86 & 10,07 & 1,47 & 4,09 & 83,51 \\
\hline Outubro & 2,81 & 32,12 & 7,11 & 4,96 & 52,99 \\
\hline Novembro & 2,09 & 38,67 & 2,24 & 1,55 & 55,44 \\
\hline Dezembro & 1,74 & 35,30 & 2,42 & 2,19 & 58,35 \\
\hline Janeiro - 76 & 0,39 & 8,58 & 0,48 & 1,02 & 89,53 \\
\hline Fevereiro & 0,45 & 12,98 & 0,55 & 0,32 & 85,70 \\
\hline Março & 1,36 & 36,12 & 2,32 & 8,53 & 51,61 \\
\hline Abril & 3,35 & 63,87 & 0,28 & 0,00 & 32,50 \\
\hline Mēdia & 2,28 & 33,99 & 4,60 & 2,61 & 56,69 \\
\hline$x^{2}$ & 14,91 & 108,55 & 92,25 & 25,97 & 43,37 \\
\hline
\end{tabular}

0 percentual da área gonadal, ocupada pelos ovócitos noes tādio $V$, sugere que a maturação gonadal, no jundiā, é contínua,porém variāvel de agosto a março, com as maiores incidências, jā apontadas, nos meses de agosto-setembro e janeiro-fevereiro.

Os resultados das Tabelas V e VI, precedentes, mostram que as maiores percentagens de ovócitos, em estādio avançado de matura 
ção, correspondem aos meses que são mais altos o peso da gonada e o IGS.

Os coeficientes ponderais da proporção de ovōcitos (CPN) e da ārea ocupada (CPT), em cada estādio, são apresentados na Tabela VII .

TABELA VII

Coeficientes ponderais da proporção de ovōcitos (CPN) e da ārea ocupada (CPT), em cada estādio, nas fēmeas de $R$. sapo coletadas na região de Santa Maria, RS (maio 1975 - abril 1976).

\begin{tabular}{lll}
\hline \hline MES & \multicolumn{1}{c}{ CPM } & CPT \\
\hline Maio -75 & $195,44^{\mathrm{f}}$ & $277,84^{\mathrm{g}}$ \\
Junho & $228,67^{\mathrm{de}}$ & $358,29^{\mathrm{e}}$ \\
Julho & $215,77^{\mathrm{def}}$ & $296,19^{\mathrm{f}}$ \\
Agosto & $283,18^{\mathrm{c}}$ & $425,00^{\mathrm{c}}$ \\
Setembro & $347,18^{\mathrm{b}}$ & $459,32^{\mathrm{b}}$ \\
Outubro & $242,86^{\mathrm{de}}$ & $373,17^{\mathrm{de}}$ \\
Novembro & $240,73^{\mathrm{de}}$ & $369,55^{\mathrm{de}}$ \\
Dezembro & $250,36^{\mathrm{d}}$ & $380,17^{\mathrm{de}}$ \\
Janeiro -76 & $380,47^{\mathrm{a}}$ & $470,72^{\mathrm{a}}$ \\
Fevereiro & $346,68^{\mathrm{ab}}$ & $457,84^{\mathrm{b}}$ \\
Março & $255,02^{\mathrm{d}}$ & $372,85^{\mathrm{d}}$ \\
Abril & $204,56^{\mathrm{f}}$ & $294,43^{\mathrm{fg}}$ \\
\hline
\end{tabular}

Os valores, na mesma coluna, com a mesma letra, não dife ferem significativamente $(P>0,05)$.

Foram detectadas diferenças altamente significativas ( $P<$ $0,01)$ entre os meses, tanto para CPN quanto para CPT. 0 teste de DUN CAN revelou que os meses de agosto, setembro, janeiro e ferereiro apresentaram coeficientes significativamente superiores $(P<0,05)$ aos demais e que, de maneira geral, os meses de abril, maio e julho pro porcionaram coeficientes mais baixos $(P<0,05)$.

Constata-se que os coeficientes CPN e CPT mostraram, com maior clareza, as mesmas tendēncias observadas nas Tabelas V e VI, sendo mais fácil vislumbar o efeito mensal em um só valor que expres sa a resposta daquele mēs, do que nas proporções de cinco estádios como anteriormente feito.

Conformando os efeitos associativos existentes entre peso 
da gônada e IGS com os coeficientes CPN e CPT, a Tabela VIII mostra correlaçöes simples positivas, de alta significāncia $(P<0,01)$.

TABELA VIII

Correlaçōes simples entre peso da gōnada (PG) e IGS comos coeficientes CPN e CPT das fêmeas de $R$. sapo coletadas na região de Santa Maria, RS (maio 1975 - abril 1976).

\begin{tabular}{ccc}
\hline ITEM & CPN & CPT \\
\hline PG & $0,778^{*}$ & $0,737^{*}$ \\
IGS & $0,816^{*}$ & $0,781^{*}$ \\
\hline
\end{tabular}

* $(P<0,01)$

Como GODINHO et alii (9), JAMES (12) e SAKSENA \& BHARGAVA (19), consideramos, neste trabalho, cinco estádios de desenvolvimen to dos ovócitos, com base nas transformações citológicas. Estes es tádios, porém, não correspondem, necessariamente, aos descritos pe los autores citados. Outros pesquisadores (1, 2, 18 e 24), levando em conta fases de transiçào, referem-se a maior nümero de etapas.

Os dados jă apresentados nas Tabelas V e VI, que demonstram um longo periodo reprodutivo e evidências de vārias desovas durante o mesmo, ievam a crer que o desenvolvimento dos ovöcitos de $R$. sapo enquadra-se na modalidade com assincronismo, descritos por MARZA, ci tado por ZANUY \& CARRILO (24), que caracteriza-se pela presença, no ovārio, em época de desova, de ovōcitos em vārios estádios de vitelo gênese. o perīodo reprodutivo é muito longo e as desovas são mūiti plas.

Vários autores $(3,4,6,10,11,13,15,16$ e 23) demons traram a influência de fatores abióticos sobre o ciclo reprodutivo dos peixes e concluiram que a temperatura, o fotoperiodo, ou a combi nação de ambos são os elementos que, mais frequentemente, inibem ou estimulam as mudanças estacionais ocorridas no desenvolvimento gona dal.

A temperatura média mensal e a duração do fotoperíodo, re gistradas ao longo do experimento, são apresentadas na Tabela IX.

Pelo exame desta tabela e dos resultados obtidos atravēs do peso da gōnada, do IGS, da percentagem mensal dos diversos estádios dos ovōcitos, da percentagem da àrea de ovārio ocupada pelos mesmos, dos CPN e CPT que, em seu conjunto, retratam o desenvolvimento gona dal do jundià ao longo deste experimento, infere-se que este desenvol vimento independe dos fatores ambientais. 
TABELA IX

Médias mensais da temperatura ambiente $\left({ }^{\circ} \mathrm{C}\right)$ e duração do fotoperiodo ( $h$ ) durante o experimento com $R$. sapo, na região de San ta Maria, RS (maio 1975 - abril 1976).

\begin{tabular}{lcc}
\hline MES & $\begin{array}{c}\text { TEMPERATURA } \\
\left({ }^{\circ} \mathrm{C}\right)\end{array}$ & $\begin{array}{c}\text { FOTOPERTODO } \\
(\text { hy }\end{array}$ \\
\hline Maio -75 & 19,5 & 11,4 \\
Junho & 15,3 & 11,1 \\
Julho & 17,1 & 11,3 \\
Agosto & 16,1 & 11,8 \\
Setembro & 16,6 & 12,7 \\
Outubro & 17,6 & 13,6 \\
Novembro & 21,0 & 14,5 \\
Dezembro & 23,6 & 15,0 \\
Janeiro & 25,1 & 14,7 \\
Fevereiro & 24,0 & 14,0 \\
Março & 21,3 & 13,1 \\
Abril & 17,1 & 12,2 \\
\hline
\end{tabular}

1 fonte: Estação Metereológica da Universidade de Santa Maria.

2 fonte: Estação Metereológica da Base Aērea de Santa Maria.

Com base nos achados de MEYER et alii (17) para o catfish (Ictalurus punctatus), concluindo que o ciclo reprodutivo pode variar de ano para ano e de um local para outro, sugere-se interpretar com cautela os achados deste trabalho.

CONCLUSOES

A análise dos resultados do presente trabalho permite as seguintes conclusões:

1. As fêmeas de jundiā (Rhamdia sapo) apresentam um longo período reprodutivo, que se estende de agosto a fevereiro, durante o qual se manifestam duas fases nitidas de acentuado desenvolvimento gonadal, correspondentes aos meses de agosto-setembro e janeiro- fe vereiro.

2. Os parâmetros empregados neste experimento (peso das gó nadas, îndice gōnado-somātico (IGS), percentagem mensal dos ovócitos nos diferentes estádios, percentagem da ārea de ovārio ocupada pelos ovōcitos nos diferentes estádios, coeficiente ponderal mensalda pro porção de ovócitos (CPN) e da área ocupada pelos ovócitos (CPT) em cada estádio), foram coincidentes na descrição do estado de maturi dade reprodutiva das fémeas estudadas. 
3. O IGS, por sua fácil obtenção e pela sua apurada acui dade, è medida de uso aconselhāvel para avaliar o estādio de deseñ volvimento gonadal em peixes.

4. Não houve evidência de um efeito nîtido dos fatores abiō ticos sobre o desenvolvimento gonadal.

5. E desaconselhāvel a pesca do jundiā nos meses de agos to-setembro e janeiro-fevereiro em vista dos aludidos aumentos da atividade reprodutiva da espécie.

\section{BIBLIOGRAFIA CITADA}

1. BARA,G. Histological and cytological changes in the ovaries of the mackarel (Scomber scomber, L.). Rev.Fac.Sei. Istambul Univ. 259 $(1-2): 49-91,1960$.

2. BARR,W.A. The endocrine control of the sexual cycle in the plaice, Pleuronectes platessa (L.). Cyclical changes in the normal ovary. General and Comparative Endocrinology 3: 197-204, 1963.

3. BASILE-MARTINS,M.A.; GODINHO,H.M.; FENERICH,N.A. \& BARKER,J.M.B. Influência de fatores abióticos sobre a maturação dos ovārios de Pimelodus maculatus Lac. 1803 (Pisces, Siluroidei). Bol. Inst. Pesca, Santos \& (1): 1-14, 1975.

4. FARNER,D.S. Comparative Physiology: photoperiodicity. Aust. J.zooz. 22: 449-456, 1974 .

5. FRANCHI,L.L. The structure of the ovary. In: ZUCKERMAN, S.S. The ovary. Vol. II, New York, Academic Press, 121-131, 1962.

6. FRAPS,R.M. Effects of external factors on the activity of the ovary. In: ZUCKERMAN, S.S. The ovary. Vol. II, New York, Aca demic Press. 317-331, 1962.

7. GANDOLFI, G. \& ORSINI,P. Alcune osservazioni sulla biologia ripró dutiva di Mugiz saliens della Laguna di Venezia. Boll. Pesca Piscic. Idrobiol. XXV (1): 85-93, 1970.

8. GODINHO,H.; FENERICH,N.A.; BASILE-MARTINS,M.A. \& BARKER, J.M.B.Ma turation curve of the ovary of Pimezodus macuzatus Lac. (Silu roidei, Teleostei). Bol. Inst. Pesca, São Paulo 3 (1): 1-20, 1974.

9. GODINHO,H.M.; FERRI,S.; MEDEIROS, L.0. \& BARKER, J.M.B. Morpholo gical chenges in the ovary of Pimezodus macuzatus Lacépède, 1803 (Pisces, Siluroidei) related to the reproductive cycle. Rev. Brasiz. Biol. 34 (4): 581-588, 1974.

10. HAYDOCK, I. Gonad maturation and hormone-induced spawning of the gulf croaker, Bairdiezla icistia. Fish. Bulz. 69 (1): 157 180,1977 .

11. HOAR,W.S. Comparative Physiology: Hormones and reproduction in 
fishes. An. Rev. Physiol. 27: 51-70, 1965.

12. JAMES,M.F. Histology of gonadal changes in the bluegill, Lepomis macrochirus (Rafinesque) and the largemouth bass, Huro salmoi des (Lacēpède). J.Morph. 79: 63-91, 1946.

13. KAYA,C.M. \& HASLER,A.D. Photoperiod and temperature effects on the gonads of green sunfish, Lepomis cyanezzus (Rafinesque), du ring the quiescent, winter phase of its annual sexual cycle. Trans.Amer.Fish Soc. 2: 270-275, 1972.

14. MACKAY,N.J. The reproductive cycle of the firetail gudgeon, Hypse leotris galii. I. Seasonal histological changes in the ovary. Aust.J.2002, 21: 53-66, 1973.

15. The reproductive cycle in the firetail gudgeon. Hypsezeotris galii. III. Environmental regulation of vitellogenesis. Aust. J.Z00Z. 22: 449-456, 1974 .

16. MATSUSHIMA, M. \& FELIX,S.S. Modification of the sexual cycle in "Wakin" Carassius carassius by hormone injection and with regu lated environmental conditions. Bull. Freshwater Fish. Res. $L a b .16$ (2): 91-102, 1966.

17: MEYER,F.P.; SNEED,K.E. \& ESCHMEYER,P.T. Second report to the fish farmers. Resource Publication 113, Bureau of sport Fisheries and Wildlife, Washington, D.C., june 1973.

18. PIGNALBERI,C.T. Evoluciōn de las gonadas en Prochizodus platen sis y ensayo de classificación de los estados sexuales - (Pis ces, Characidae). Anais do II Congresso Latinoamericano de Zoologia, São Paulo II, 203-208, 1965.

19. SAKSENA,D.N. \& BHARGAVA,H.A. The corpora atretica, post-ovulato ry follicles and spawning periodicity of Indian fresh-water goby. Glossogobios giuris (Ham.). Zool. Th. Anat.Bd 89, S. $611-620,1972$.

20. SCHUBART,0. A classificação dos estados sexuaís do curimbatá. Bol. Minist. de Agric., Rio de Janeiro $36 ; 1-13,1947$.

21. SHIRAISHI,Y. \& FUKUDA,I. The relation between the day length and the maturation in four species of salmonid fishes. Bulz. Fresh water Fish. Res. Lab. 16 (2): 103-11, 1966.

22. SILVA,S.S. de. Aspects of the reproductive biology os the sprat. sprattus sprattus (L.) in inshore waters of the west coast of Scotland. J.Fish. Biol. 5:689-705, 1973.

23. SUNDARARAJ.B.I. \& SEHGAL, A. Effects of a long or an increasing photoperiod on the initiation of ovarian recrudescence during the preparatory period in the catfish, Heteropneustes fossilis (Bloch). Biology of Reproduction 2: 413-424, 1970. 
24. ZANUY,S. \& CARRILLO,M. Estudio histolögico del ovario de cabrilla (Paracentropristes cabrizza) (L.) en relaciōn com la ovogéne sis. Inv. Pesq. 37 (1): 147-165, 1973.

Recebido em junho, 1980; aceito em julho, 1980. 
